\title{
ESTUDO INTEGRATIVO ENTRE TRÊS PARÂMETROS AMBIENTAIS (TEMPERATURA, UMIDADE RELATIVA DO AR E VELOCIDADE DO VENTO), FAUNA EPÍGEA E VEGETAÇÃO EM FLORESTAS URBANAS
}

\author{
Ana Júlia da Silva Moura; Kevin de Oliveira Moura; Letícia Picanço da Silva; \\ Rafael Dias Bicalho; Antônio Pereira Júnior. \\ DOI: $10.4322 / 978-85-455202-1-4-12$
}

\section{INTRODUÇÃO}

A qualidade do solo se relaciona aos sucessivos processos biológicos e físico-químicos que são influenciados diretamente pelas condições ambientais presentes no meio de estudo (MUSCOLO, 2014; SCORIZA, 2016b). Desta forma, a análise de variáveis como umidade relativa do ar, temperatura e intensidade de vento se apresenta como importante ferramenta para análise dos efeitos de impactos resultantes da intervenção humana ou identificação de etapas de regeneração natural da área.

O estudo acerca da comunidade epígea contribui significativamente para a manutenção da qualidade dos solos. Neste sentido, a análise da frequências e distribuição dos seres vivos, bioindicadores da qualidade do solo, aliada à de condições microclimáticas e serapilheira, possibilita avaliar e considerar interferências antrópicas em um ecossistema (PATUCCI, 2017; SCORIZA, 2016a). A ecologia natural, área do pensamento ecológico, dedica-se a analisar o funcionamento de sistemas naturais, como florestas, oceanos, etc., entender a dinâmica de vida da natureza e se vale de fundamentos de várias ciências como a química, física e geologia (LAGO; PÁDUA, 2017). Neste sentido, compreender a interação entre a fauna e variáveis e características ambientais é de extrema relevância para avaliar certa área ou ainda fazer o planejamento desta.

Em decorrência do aumento populacional, foi verificado um crescimento exponencial no que diz respeito à urbanização e desenvolvimento de cidades. As cidades, ao contrário de serem locais homogêneos, possuem zoneamentos conforme o tipo de atividade pretendida ou uso dado a áreas (parques, zona industrial, zona residencial) (RODRIGUES; BORGES-MARTINS; ZILIO; 2018).

A migração de pessoas de áreas rurais para as cidades e vilas foi também um dos fatores determinantes para enveredar a expansão urbana. Assim, desde o ano de 2008, a maior parte da população mundial habita em espaços urbanos e esta estimativa tende a atingir aproximadamente $70 \%$ em 2050, posto que a alteração de paisagens provoca a criação de microclimas cuja temperatura, índice de precipitação e vento diferem-se daqueles do entorno (SALBITANO et al., 2016).

Neste contexto, a intensa atividade antrópica e modificação do meio causou impactos negativos para o próprio. O debate público acerca de temas ambientais deu-se apenas um período após o tema ter acedido à agenda internacional e as leis brasileiras iniciais que visavam à proteção do meio ambiente estavam estritamente relacionadas a problemas de poluição (SÁNCHEZ, 2013).

Devido à retirada da cobertura vegetal e asfaltamento de cidades e rodovias, houve significativa mudança de temperatura, fator que pode ocasionar desconforto térmico de habitantes. Em vista disso, algumas cidades optam por construir áreas verdes de conservação, o que intervém diretamente no conforto térmico nas proximidades. Isto é, a arborização ameniza considerável quantidade da radiação incidente, o que garante que a menor parte de raios solares atinjam a superfície, além de que a evapotranspiração advinda da vegetação favorece o resfriamento do ambiente (LABAKI et al., 2011).

As florestas urbanas representam para cidades uma forte influência no turismo, paisagismo e ainda na história local. A utilidade de florestas secundárias urbanas para cidades tem sido ressaltada por gestores públicos e moradores, uma vez que as mesmas proporcionam serviços e proveitos no 
que diz respeito à vida, conforto ambiental, redução de poluentes do ar, além do convívio com elementos naturais, dentre outros (SANTANA; FREITAS; MAGALHÃES; 2015).

Parques ecológicos são excelentes exemplos de área verde em um município. No âmbito de políticas públicas, segundo o Sistema Nacional de Unidades de Conservação - (SNUC), instituído pela Lei N. 9.986, de 18 de julho de 2000, Parque Nacional pode ser definido como uma das categorias de unidade de conservação. Quando uma unidade de conservação dessa categoria é criada pelo Estado, esta é tida como Parque Estadual. Uma vez criada pelos municípios, é denominada Parque Natural Municipal (LUNAS; RIBAS, 2013).

Nessa conjuntura, no que diz respeito ao município de Paragominas, localizado no estado do Pará, até 2008, a cidade já havia eliminado $43 \%$ de sua área florestal por meio de atividades madeireiras, moveleiras, além de carvoarias que ocasionavam o desmatamento e poluição ambiental, uma vez que as mesmas práticas não eram fiscalizadas e/ou até mesmo regularizadas por órgãos competentes (ALVES; PALHETA; ANDRADE, 2015). Como forma de reverter tal cenário, foi implantado o Projeto de Política Pública, intitulado de "Programa Município Verde", desenvolvido pela Fundação Vale (COSTA; FLEURY, 2015).

Enfim, os problemas ambientais são diversos e constantes, e isso justificou esta pesquisa bem como incrementou a relevância da mesma, cujo objetivo foi analisar de forma quantitativa e qualitativa a interação entre três parâmetros atmosféricos (temperatura, umidade relativa do ar e velocidade do vento), a pedofauna e a vegetação em floresta urbana, apresentará informações de profunda relevância para modesta compreensão do funcionamento do Parque Ambiental Adhemar Monteiro, no município de Paragominas - PA além de propor recomendações para favorecer o processo de reabilitação da área.

\section{MATERIAL E MÉTODOS}

\section{FISIOGR AFIA DO MUNICÍPIO}

O município de Paragominas (Figura 1), é localizado na mesorregião sudeste do estado do Pará, detém a área de 19.342,254 quilômetros quadrados e população de 110.026 habitantes de acordo com a estimativa realizada pelo IBGE no ano de 2017 (IBGE, 2018). O clima da região é tropical quente e úmido, a temperatura média do município anualmente é de $26,3^{\circ} \mathrm{C}$, referente a umidade relativa do ar anualmente é de $81 \%$ (ALVES; CARVALHO; SILVA, 2014).

Figura 1 - Localização do município de Paragominas - PA.

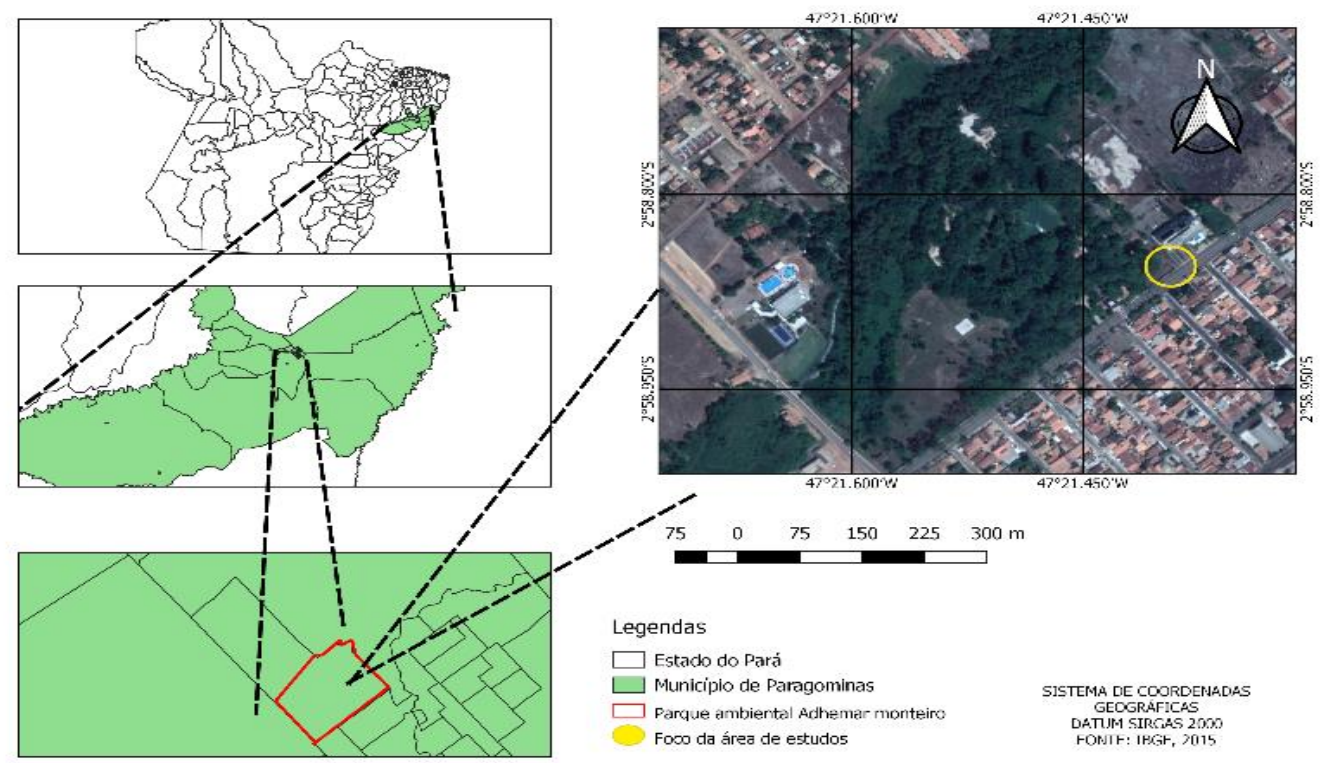


Fonte: autores (2018)

\section{ÁREA DO ESTUDO}

A área de estudo localiza-se no interior do Parque Ambiental Adhemar Monteiro, onde se encontra uma floresta urbana sob a forma de Unidade de Conservação (UC). Foi delimitada, no sentido leste, a partir do protão de acesso do Parque, distante da cerca aramada, uma área total 100 $\mathrm{m}^{2}$, com perímetro de aproximadamente $40 \mathrm{~m}$ (Figura 2).

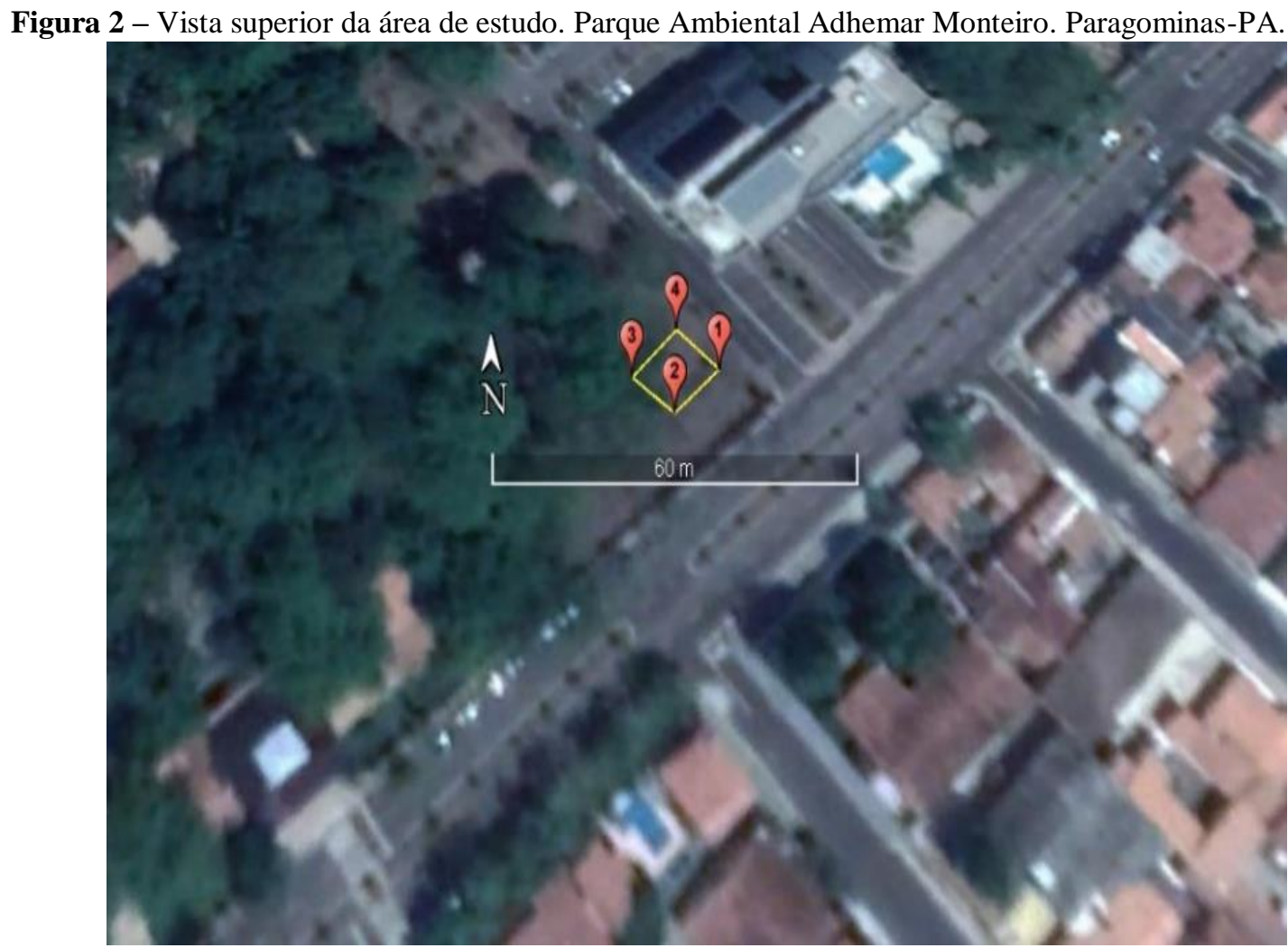

Fonte: Google Earth (2017).

Os quatro pontos que delimitam a área foram nomeados de $\mathrm{P}_{1}, \mathrm{P}_{2}, \mathrm{P}_{3}$ e $\mathrm{P}_{4}$, a partir dos quais, obteve-se o posicionamento planialtimétrico, no sentido horário, do ponto $\mathrm{P}_{1}$ para $\mathrm{P}_{4}$ e em projeção transversal de Mercator, cuja sigla em inglês é UTM (Tabela 1).

Tabela 1 - Coordenadas geográficas dos quatro pontos que delimitam a área de estudo. Paragominas- PA.

\begin{tabular}{|c|c|c|}
\hline PONTO & LATITUDE (UTM) & LONGITUDE (UTM) \\
\hline $\mathrm{P} 1$ & $23 \mathrm{M} 0238056 \mathrm{~m} \mathrm{E}$ & 23 M $9670243 \mathrm{~m} \mathrm{~S}$ \\
\hline $\mathrm{P} 2$ & $23 \mathrm{M} 0238050 \mathrm{~m} \mathrm{E}$ & $23 \mathrm{M} 9670237 \mathrm{~m} \mathrm{~S}$ \\
\hline P3 & $23 \mathrm{M} 0238043 \mathrm{~m} \mathrm{E}$ & 23 M $9670244 m$ S \\
\hline P4 & $23 \mathrm{M} 0238052 \mathrm{~m} \mathrm{E}$ & 23 M 9670248m S \\
\hline
\end{tabular}

\section{ÁREAS ADJACENTES}

Verificou-se também que, em volta da área de estudo, existem áreas que apresentam fauna, flora, presença de resíduos sólidos que podem influenciar direta ou indiretamente sobre a área delimitada para esse estudo (Figura 3). 
Figura 3 - Croqui da área de estudo e áreas adjacentes. Parque Ambiental Adhemar Monteiro. Paragominas-PA

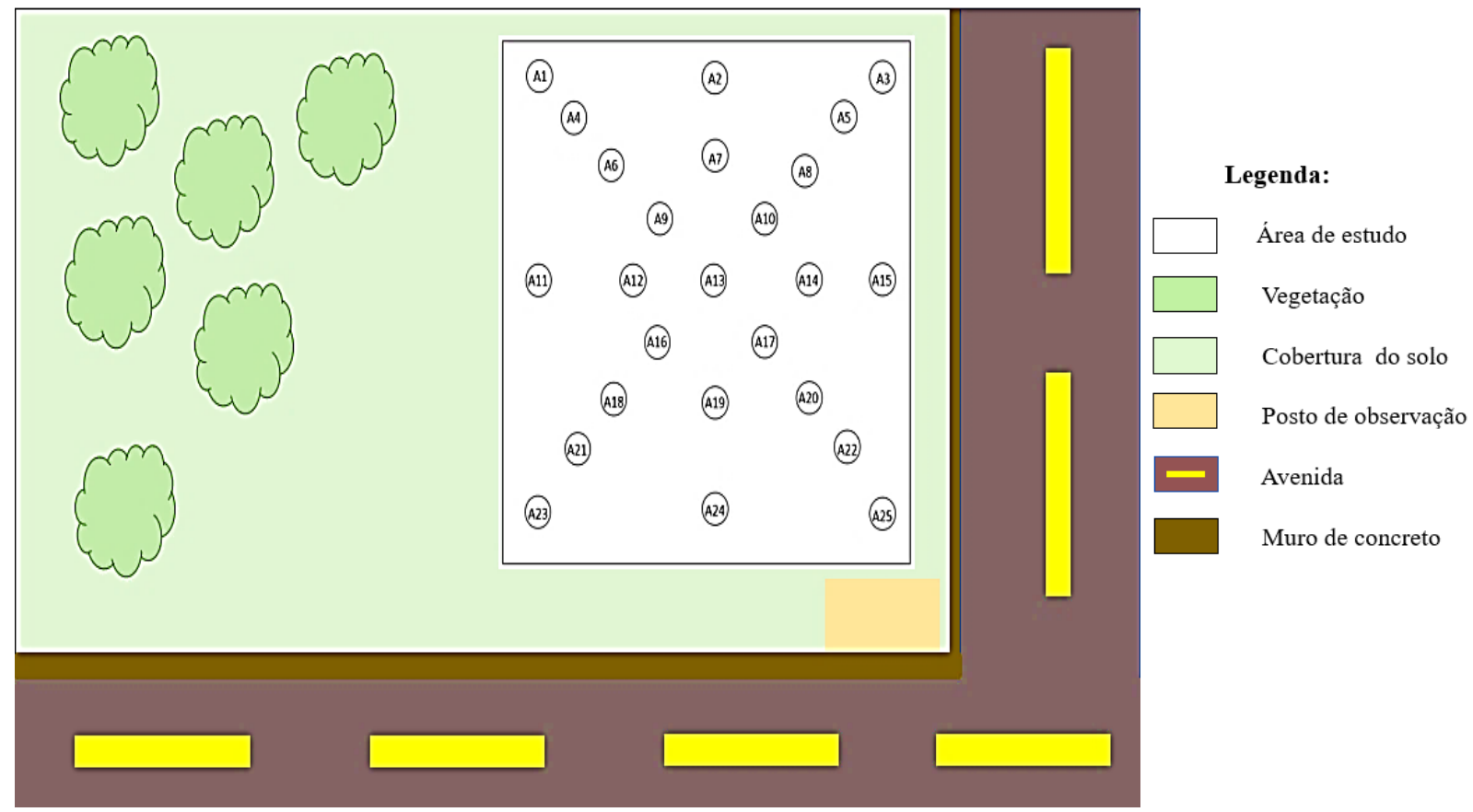

Fonte: autores (2018).

\section{COLETA DE DADOS}

Os dados foram coletados nos dias 15 a 18 de agosto de 2018, nos quais foram mensurados três parâmetros ambientais (temperatura, umidade relativa do ar e velocidade do vento), observadas as características fisiográficas do local, amostragem da pedofauna através das Pitfall traps (Quadro $1)$.

Quadro 1 - Atividades realizadas em campo, conforme dia de visita. Parque Ambiental Adhemar Monteiro.

Paragominas-PA

\begin{tabular}{|c|c|c|}
\hline DIA & P.V. & ATIVIDADES REALIZADAS \\
\hline 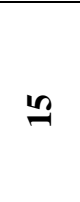 & 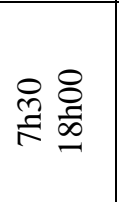 & $\begin{array}{l}\text { Ao chegar ao local, foi feita a delimitação da área de estudo e registro das coordenadas } \\
\text { geográficas. Posteriormente, foi instalado o abrigo meteorológico para o Termo higrômetro e a } \\
\text { partir das 9:00h foi mensurada a umidade relativa do ar por meio da verificação das } \\
\text { temperaturas apontadas nos bulbos seco e úmido, e a velocidade do vento a cada hora até as } \\
\text { 17:00h. Além disso foi preparado vinte e cinco covas para as traps e a instalação de } 13 \text { delas. }\end{array}$ \\
\hline$\underset{1}{2}$ & $\begin{array}{l}\circ 8 \\
\text { 을 } \\
\text { 을 }\end{array}$ & $\begin{array}{l}\text { No segundo dia, foi acoplado o abrigo meteorológico e em e posteriormente foram } \\
\text { aferidos novamente os valores de velocidade do vento e temperatura, a partir das 7:00h até as } \\
\text { 17:00h, de uma em uma hora, além disso, foram preparadas as armadilhas restantes. }\end{array}$ \\
\hline ニ & 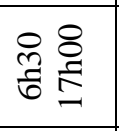 & $\begin{array}{l}\text { No terceiro dia, foi acoplado o abrigo meteorológico e em seguida foi feita a } \\
\text { mensuração dos valores de temperatura e velocidade do vento, com início às 7:00h até as 17:00h } \\
\text { a cada uma hora, além disso, foi feita a recarga da solução paralisante nas armadilhas }\end{array}$ \\
\hline$\stackrel{\infty}{\sim}$ & 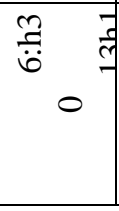 & $\begin{array}{l}\text { No último dia foi preparado o abrigo meteorológico e em seguida foram aferidos os } \\
\text { valores de temperatura e velocidade do vento novamente, a partir das } 7: 00 \mathrm{~h} \text { até às } 12: 00 \mathrm{~h} \text { a } \\
\text { cada uma hora, além disso, foram retiradas as armadilhas. etiquetadas e lacradas. Em seguida, } \\
\text { foram armazenadas em caixas de papelão e levadas ao laboratório de qualidade ambiental na } \\
\text { UEPA campus VI. }\end{array}$ \\
\hline
\end{tabular}

Fonte: autores (2018).

Em relação a coleta da fauna epígea, foram implantadas 25 armadilhas de queda (Figura 3), em inglês pitfall traps (AQUINO; CORREIA, 2005) na área delimitada. 
Figura 4- a) armadilhas de queda pitfall traps alocadas na área destina a pesquisa; b) Coleta intervalar de dados referentes às variáveis ambientais. Parque Ambiental Adhemar Monteiro. Paragominas - PA.

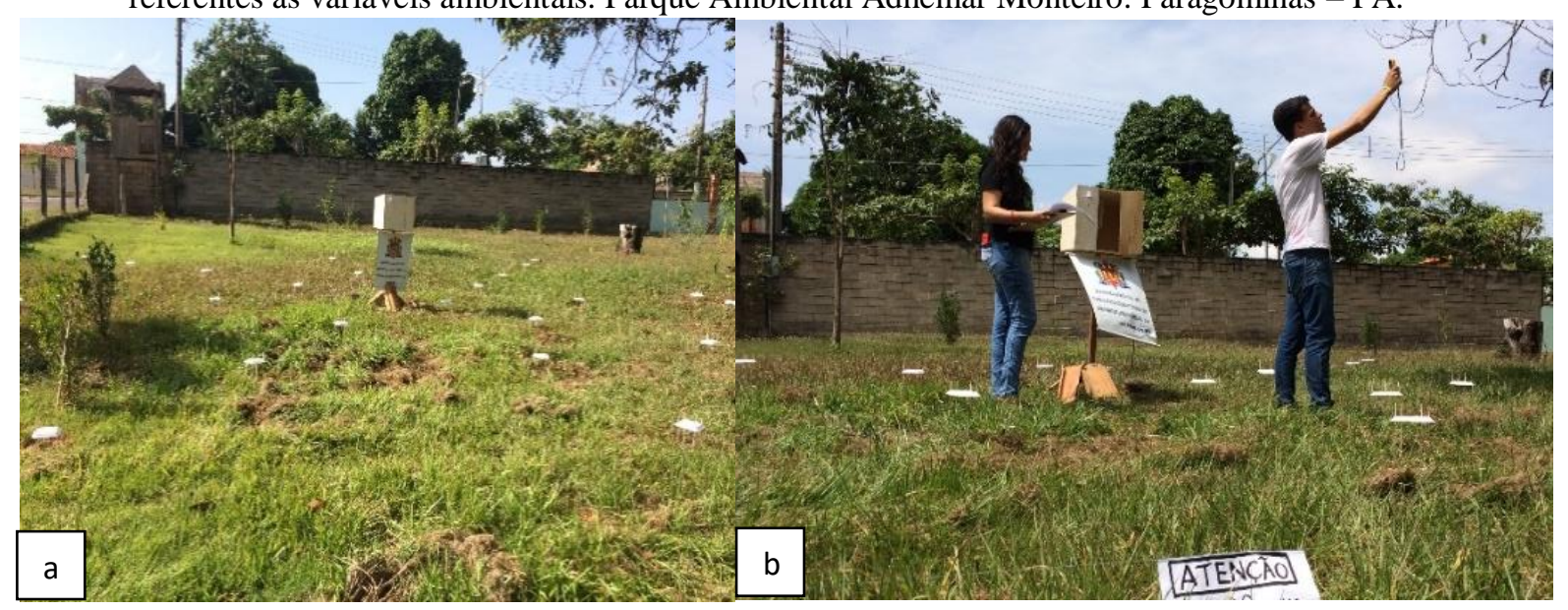

Fonte: autores (2018)

Em cada uma delas, colocou-se $150 \mathrm{~mL}$ da substância paralisante $(970 \mathrm{ml}$ de água destilada, $28 \mathrm{ml}$ de clorofórmio, três gotas de biodetergente) que ficaram durante quatro dias na área da pesquisa. Logo após elas foram retiradas, etiquetadas, lacradas e transportadas para o Laboratório de Qualidade Ambiental para identificação de acordo com as chaves classificatórias já preconizadas em estudos pioneiros (RUPPERT; BARNES, 1996).

Quanto a mensuração dos três parâmetros ambientais na área estudada, esta foi realizada com os equipamentos cedidos pelo Laboratório de Qualidade Ambiental da Universidade do Estado do Pará, Campus VI, Paragominas: anemômetro (Figura 5a), Psicrômetro (Figura 5b) e Global Positioning System (Figura 5c). A precisão de cada equipamento foi garantida pelos fabricantes pois forneceram certificações da calibração.

Figura 5 - a) anemômetro; b) psicrômetro; e c) Global Positioning System - GPS.

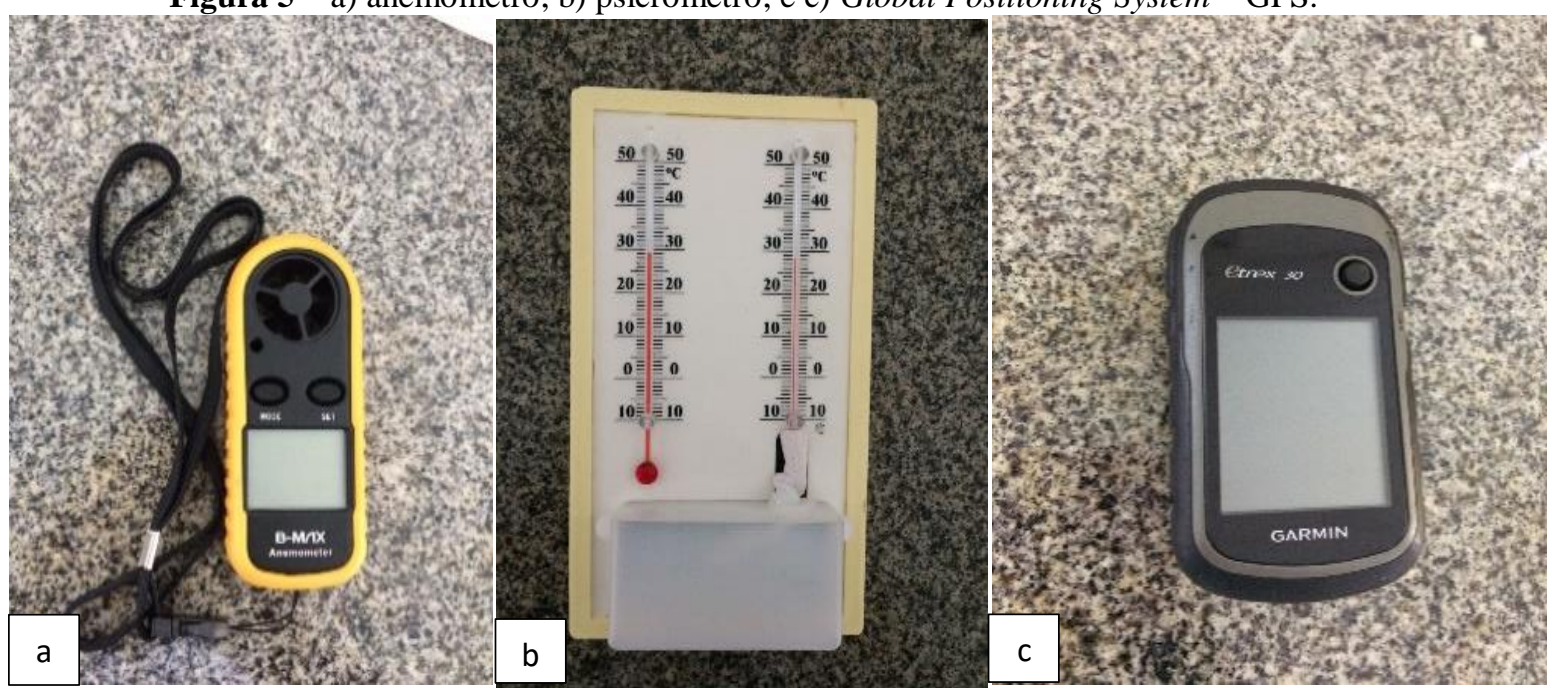

Fonte: autores (2018).

A precisão de cada equipamento é dada de acordo com seus respectivos modelo e marca (Tabela 2). 
Tabela 2 - Equipamentos utilizados para mensurações dos parâmetros atmosféricos. Parque Ambiental Adhemar Monteiro. Paragominas - PA.

\begin{tabular}{ccccc}
\hline EQUIPAMENTO & MARCA & MODELO & UTILIDADE & UNIDADE \\
\hline $\begin{array}{c}\text { Anemômetro } \\
\text { Diastimetro }\end{array}$ & Benetech & GM816 & Mensurar a velocidade do vento & $\mathrm{m} / \mathrm{s}$ \\
& Starrett & Tx1-10ME & Mensurar a distância entre dois pontos & $\begin{array}{c}\mathrm{cm} \\
\text { Graus, } \\
\text { minutos e }\end{array}$ \\
GPS & Gramim & ETREX30S & Coordenadas planialtimétricas & $\begin{array}{c}\text { segundos } \\
\text { Psicrômetro }\end{array}$ \\
& Incoterm & AS 5195 & Mensurar a temperatura seca e úmida & ${ }^{\circ} \mathrm{C}$ \\
\hline
\end{tabular}
Fonte: autores (2018).

Essas mensurações foram necessárias porque o estudo tem foco interativo entre esses parâmetros, a fauna epígea e a vegetação, logo, deve-se conhecer a interação entre a umidade relativa do ar, direção e velocidade do vento, dominância de superfícies construídas, ausência de vegetação o que caracteriza a presença de poluição ambiental (MASCARO, 2018). Além dos equipamentos, foram utilizados outros materiais de acordo com sua respectiva aplicação (Tabela 3).

Tabela 3 - Materiais utilizados na pesquisa. Parque Ambiental Adhemar Monteiro. Paragominas - PA.

\begin{tabular}{llc}
\hline \multicolumn{1}{c}{ MATERIAL } & \multicolumn{1}{c}{ UTILIDADE } & QUANTIDADE \\
\hline Abrigo meteorológico & Proteção do psicrômetro & 1 Unidade \\
Bandejas de isopor & Proteção das Pitfall Traps & 30 Unidades \\
Draga & Cavar trincheiras & 2 Unidades \\
Enxada & Retirar a vegetação de gramíneas & 1 Unidade \\
Ferro de cova & Descompactação do solo & 1 Unidade \\
Galão de 20L & Armazenamento da solução paralisante & 1 Unidade \\
Hastes de madeira & Suporte para as bandejas de isopor & 125 Unidades \\
Linha de nylon & Delimitar e proteger a área de estudo & 50 Metros \\
Nível de mão & Aferir o nivelamento do abrigo meteorológico & 1 Unidade \\
Proveta de 100ml & Medir a quantidade de solução para as armadilhas & 1 Unidade \\
Solução paralisante & Capturar a pedofauna & 5 Litros \\
Vasilhames de plástico de & & \\
$500 m l$ & Armazenar a solução paralisante e a pedofauna & 25 Unidades \\
\hline
\end{tabular}

Fonte: autores (2018).

\section{MÉTODO}

O método utilizado foi método dedutivo, pois fora realizada síntese, análise e enumeração dos dados, como exposto por Gerhard e Silveira (2009) coletados das variáveis ambientais e da captura de uma amostra da fauna, visando encontrar as variações de dados que explanassem as consequências das ações antrópicas no meio. Tal método foi acrescido com o levantamento de dados documentais que apresentaram um recorte temporal situado entre 2008 e 2018, devido aos últimos anos de trabalhos recentes, para uma melhor avaliação de impacto ambiental.

As bases para esse levantamento foram: Science Eletronic Library Online (SciELO), Coordenação de Pesquisa e Aperfeiçoamento do Ensino Superior (CAPES), periódicos e GOOGLE SCHOLAR. Em relação à pesquisa, ela apresenta abordagem quantitativa, onde teve-se como base o paradigma experimental. O modelo quantitativo evidencia-se por formular hipóteses prévias e técnicas de verificação sistemática, para se obter explicações causais para os fenômenos estudados. (LANDIM et al., 2012). 


\section{TRATAMENTO ESTATÍSTICO DOS DADOS}

A contagem da fauna epígea foi efetuada a partir da adaptação realizada no método preconizado por Aquino e Correia (2005). A adaptação foi necessária devido a permanência por um período inferior a sete dias. Ela reside na contagem por vasilhas coletadas e, em seguida, o cálculo da média aritmética por vasilha.

Quanto aos dados dos parâmetros atmosféricos, eles foram tratados estatisticamente com o uso de planilhas eletrônicas contidas no software Excel (MICROSOFT CORPORATION, 2016). Em seguida, aplicou-se a Estatistica Descritiva (média, desvio padrão, coeficiente de variação). Para o cálculo do coeficiente de correlação de Pearson $(r)$ foi utilizado o software BioEstat 5.3, sendo que a correlação de Pearson, pois, necessita-se verificar a intensidade da relação entre temperatura e umidade do ar, além da velocidade dos ventos. Os valores utilizados para $r$ (Tabela 3), foram adaptados em pesquisas anteriores (FIGUEIREDO FILHO; SILVA JÚNIOR, 2009; PORTO, JESUS, PEREIRA JÚNIOR, 2017) e, quanto mais perto de 1 terá uma relação direta e forte e quanto mais perto de -1 terá uma relação forte, porém inversa.

Tabela 3 - Valores utilizados para $r$.

\begin{tabular}{ccc}
\hline Valores & Caracterização & Relação \\
\hline 0 & Não há & Não há \\
\hline 0,10 a 0,30 & Correlação fraca & Direta \\
$-0,10$ a $-0,30$ & Correlação fraca & Inversa \\
0,40 a 0,60 & Correção média & Direta \\
$-0,40$ a $-0,60$ & Correlação média & Inversa \\
0,70 a 1,00 & Correlação forte & Direta \\
$-0,70$ a $-1,00$ & Correlação forte & Inversa \\
\hline
\end{tabular}

Adaptada a partir dos dados contidos em Figueiredo Filho (2009) e Porto, Jesus e Pereira Júnior (2017).

\section{RESULTADOS E DISCUSSÃO}

\section{PARÂMETROS ATMOSFÉRICOS}

Quanto à análise de dados obtidos para temperatura, foram dispostos os valores de amplitude térmica inerentes a cada horário de mensuração de cada dia no local de estudo (Figura 6).

Figura 6 - Amplitude Térmica registrada para 12 horas. Parque Ambiental Adhemar Monteiro. Paragominas PA

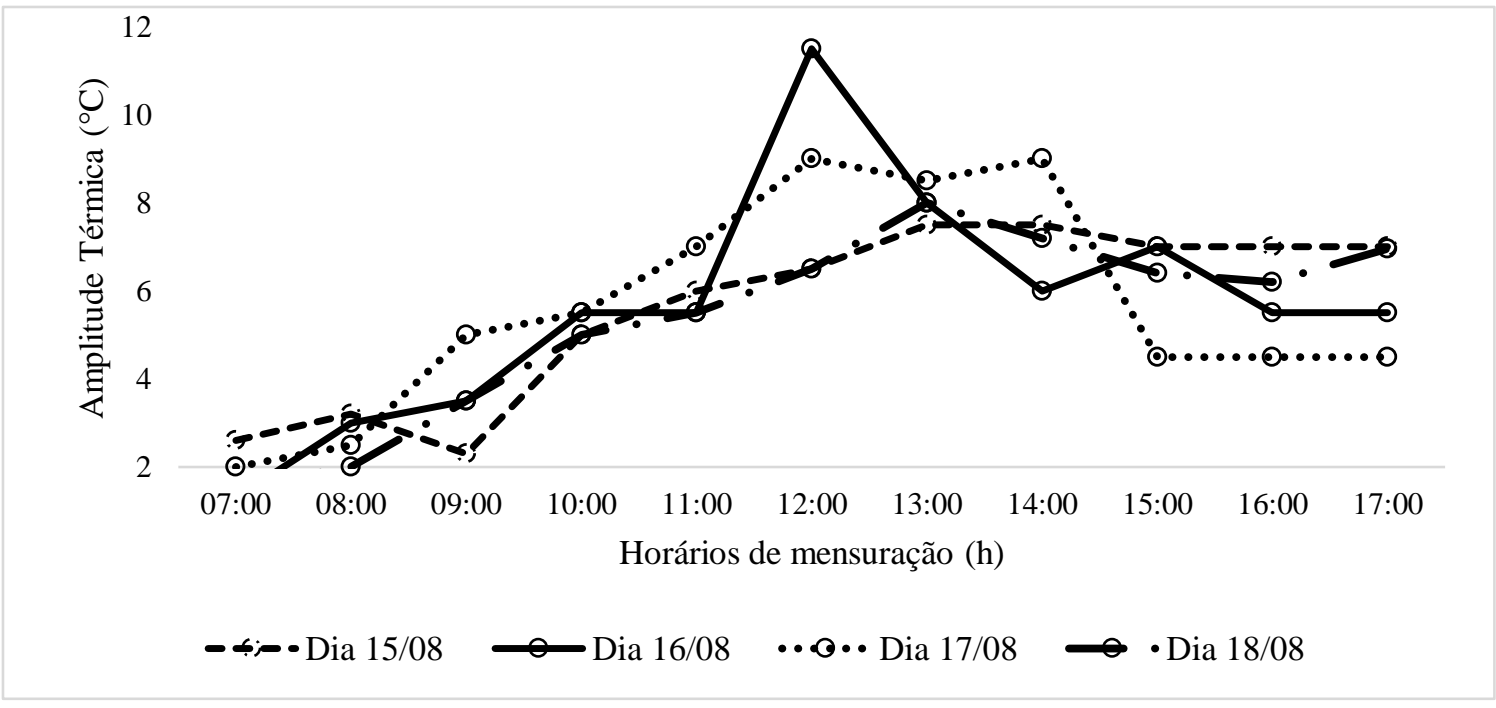

Fonte: autores (2018) 
A análise dos dados adquiridos apontou predisposição significativa de elevação entre $0700 \mathrm{~h}$ às 12:00h durante o período da pesquisa. No estudo efetuado por Santos e Galvani (2016), no perfil topoclimático da Trilha Caminhos do Mar - SP, os autores concluíram que a radiação solar e o balanço de radiação em superfícies, que são determinantes para distribuição horária da temperatura, desta forma, os maiores valores referentes à temperatura diária tendem a ocorrer de 2 a 3 foras após o pico de energia radiante, devido ao tempo que a atmosfera leva para se aquecer entre a superfície do solo e a altura padrão de medidas de temperatura do ar, em média.

Já em relação aos valores das 13:00h as 17:00h, a análise dos dados obtidos indicou que, a máxima amplitude térmica $\left(7,5^{\circ} \mathrm{C}\right)$, ocorreu no primeiro dia $(15 / 08 / 2018$, às $13: 00 \mathrm{~h})$, com tendência a estabilidade até às $14: 00 \mathrm{~h}$, com tendência a diminuição $\left(-0,5^{\circ} \mathrm{C}\right)$ até o horário medição posterior (14h00). Tal valor equivalente a $7^{\circ} \mathrm{C}$ permaneceu estável entre $15 \mathrm{~h}$ e $17 \mathrm{~h}$. Neste contexto, é esperado que, sob valores mais amenos de temperaturas, as diferenças de temperatura entre diversos pontos da cidade se manifestem de maneira mais distinta (GARTLAND, 2010).

No segundo, terceiro e quarto dias, dia 16, 17 e 18 de agosto, respectivamente, a mesma situação de tendência de acréscimo quanto à amplitude térmica foi indicada ao longo das primeiras seis horas, gradativamente. No que diz respeito aos horários subsequentes, houve tendência à diminuição gradativa até às 14:00 visto que às $15 \mathrm{~h}$ foi registrado um ligeiro acréscimo na temperatura, em seguida, redução até a última medição (exceto no último dia em virtude de as mensurações terem sido encerradas às 12:00h). É válido ressaltar que no dia 17 , houve uma brusca diminuição de amplitude registrada entre 14:00h e 15:00h, decorrente de uma leve precipitação, com início às 14:15h, uma vez que a nebulosidade, assim como entrada de frente frias ao longo dia, entre outros controles da atmosfera, influem nas variações (SANTOS; GALVANI, 2016).

Foram correlacionadas entre si as médias de valores das variáveis (umidade relativa do ar, temperatura e velocidade do vento) de cada dia do local de estudo (Figuras 7a, 7b e 7c).

Figura 7 - a) Correlação entre temperatura e umidade relativa; b) Correlação entre temperatura e velocidade do vento; c) Correlação da umidade relativa e velocidade do vento.

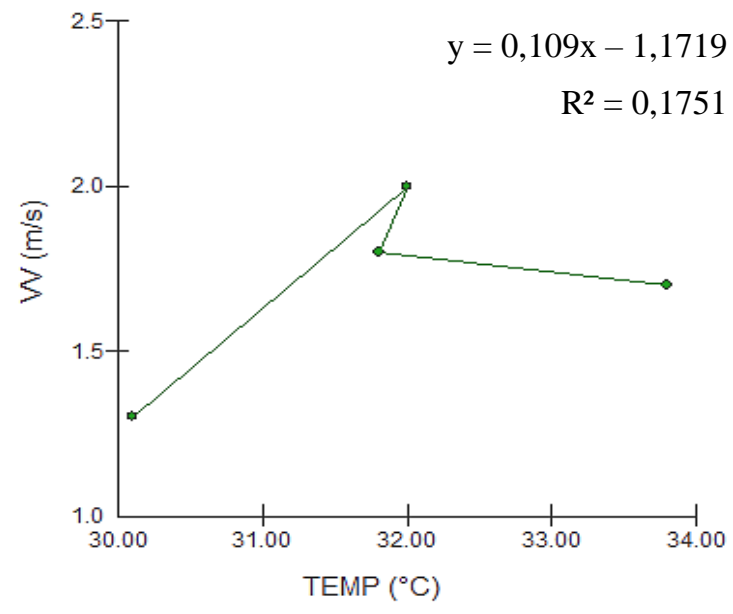

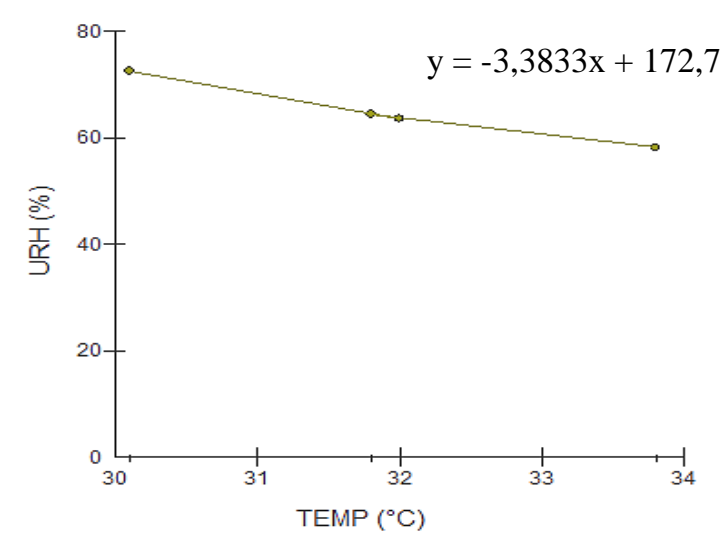




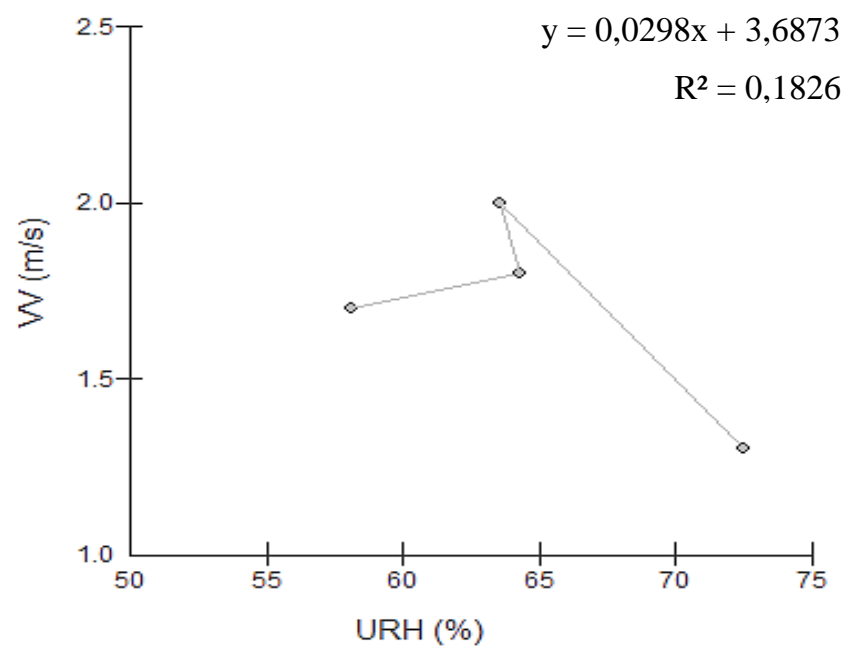

Fonte: autores (2018)

A análise dos dados do coeficiente de Pearson indicou uma correlação muito forte entre temperatura e umidade relativa do ar $(r=-0,9886)$, porém, as correlações entre a temperatura e a velocidade do vento $(r=0,5538)$ e umidade relativa e a velocidade do vento $(r=-0,6656)$, foram médias. Esta segunda apresentou um valor de aproximadamente 0,5 , logo, quando um aumenta ou diminui o outro irá aumentar ou diminuir a metade da medida do outro.

A temperatura e umidade relativa são grandezas inversamente proporcionais. Isto é, a umidade relativa apresenta comportamento inverso à temperatura. Tal fator é facilmente notado uma vez que os picos referente aos valores de umidade relativa do ar são registrados, em todos os casos estudados (com exceção do último dia, posto que a mensuração foi encerrada às 12:00h), na primeira mensuração do dia, visto que chega a atingir até mesmo $87 \%$ no segundo dia de análise, 18 de agosto.

Ao se aproximar de 12:00h, os valores tendem a diminuir e se elevarem novamente a partir das 15:00h no primeiro dia (de 55\% para 56\%), a partir das 13:00h no segundo dia (de 38\% para $53 \%$ ) e às 13:00h no terceiro dia (de $48 \%$ para $49 \%$ ). Estudo realizado no Pantanal - MT por Galeano et.al. (2013) apresentou exatamente o inverso no que se refere à temperatura: acréscimo nas horas iniciais do dia e decréscimo no final da tarde, cuja explicação consiste em os raios solares estarem mais próximos ao ângulo zenital da superfície analisada, o que ocasiona o aumento da temperatura pela energia proveniente de raios solares.

\section{FAUNA EPÍGEA}

Quanto à distribuição de indivíduos, as armadilhas de queda foram posicionadas ordinalmente nos quadrantes, infralinhas e ponto fiduciário (Figura 5). 
Figura 5 - Armadilhas de queda dispostas por ordem nos quadrantes, infralinhas e ponto fiduciário. Paragominas - PA

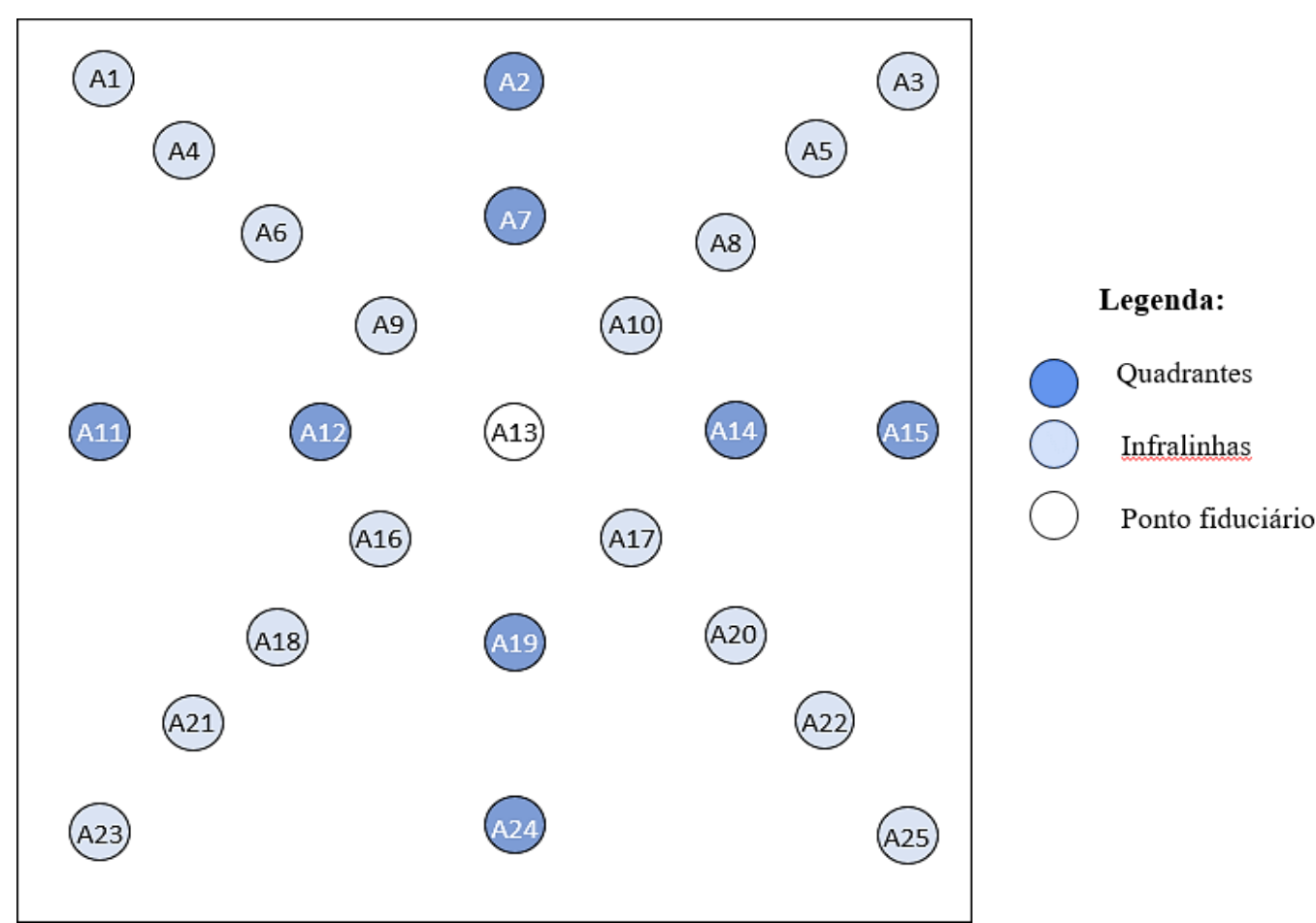

Fonte: autores (2018)

Quanto à identificação e quantificação, foi estabelecido o número de indivíduos capturados de acordo com sua respectiva ordem por quadrante (Tabela 4),

Tabela 4 - Número de indivíduos amostrados por quadrante da área. Paragominas - PA

\begin{tabular}{|c|c|c|c|c|c|c|c|c|c|c|c|c|c|c|c|c|}
\hline \multirow[b]{2}{*}{ Ordens } & \multicolumn{4}{|c|}{ Q1 } & \multicolumn{4}{|c|}{$\mathbf{Q 2}$} & \multicolumn{4}{|c|}{ Q3 } & \multicolumn{4}{|c|}{ Q4 } \\
\hline & $\mathbf{A}_{1}$ & $\mathbf{A}_{4}$ & $\mathbf{A}_{6}$ & A9 & $\mathbf{A}_{3}$ & $\mathbf{A}_{5}$ & $\mathbf{A s}_{8}$ & $\mathbf{A}_{10}$ & $\mathbf{A}_{17}$ & $\mathbf{A}_{20}$ & $\mathbf{A}_{22}$ & $\mathbf{A}_{25}$ & $\mathbf{A}_{16}$ & $\mathbf{A}_{18}$ & $\mathbf{A}_{21}$ & $\mathbf{A}_{23}$ \\
\hline Araneae & 0 & 1 & 2 & 4 & 3 & 6 & 4 & 7 & 0 & 0 & 1 & 0 & 1 & 1 & 0 & 0 \\
\hline Coleoptera & 0 & 0 & 0 & 1 & 0 & 1 & 0 & 0 & 0 & 1 & 0 & 0 & 0 & 0 & 0 & 0 \\
\hline Diplura & 0 & 0 & 0 & 0 & 0 & 1 & 0 & 0 & 0 & 0 & 0 & 0 & 0 & 1 & 0 & 0 \\
\hline Hymenoptera & 5 & 27 & 9 & 31 & 19 & 83 & 62 & 31 & 3 & 10 & 10 & 38 & 9 & 36 & 1 & 4 \\
\hline Isopoda & 0 & 0 & 0 & 0 & 0 & 0 & 0 & 0 & 0 & 0 & 1 & 0 & 0 & 0 & 0 & 0 \\
\hline Isoptera & 1 & 0 & 0 & 0 & 0 & 0 & 0 & 0 & 0 & 0 & 0 & 0 & 2 & 0 & 1 & 1 \\
\hline Psocoptera & 1 & 0 & 0 & 0 & 1 & 1 & 0 & 0 & 0 & 0 & 2 & 1 & 0 & 0 & 0 & 0 \\
\hline Orthoptera & 0 & 0 & 1 & 0 & 0 & 0 & 0 & 0 & 0 & 0 & 0 & 0 & 0 & 0 & 0 & 1 \\
\hline
\end{tabular}

Além do número e classificação por ordem de indivíduos capturados em infralinhas e ponto fiduciário (Tabela 5). 
Tabela 5 - Número de indivíduos amostrados, por ordem, nas infralinhas e ponto fiduciário. Paragominas - PA

\begin{tabular}{cccccccccc|c}
\hline & \multicolumn{7}{c|}{ Infralinhas } & PF \\
\cline { 2 - 11 } Ordem & $\mathbf{A}_{2}$ & $\mathbf{A}_{7}$ & $\mathbf{A}_{14}$ & $\mathbf{A}_{15}$ & $\mathbf{A}_{19}$ & $\mathbf{A}_{24}$ & $\mathbf{A}_{11}$ & $\mathbf{A}_{12}$ & $\mathbf{A}_{13}$ \\
\hline Araneae & 4 & 5 & 4 & 3 & 1 & 1 & 3 & 3 & 0 \\
Hymenoptera & 318 & 14 & 15 & 17 & 5 & 0 & 30 & 18 & 9 \\
Isoptera & 0 & 0 & 0 & 0 & 0 & 0 & 0 & 6 & 0 \\
Protura & 2 & 0 & 0 & 0 & 0 & 0 & 0 & 0 & 0 \\
Psocoptera & 4 & 0 & 0 & 0 & 0 & 0 & 0 & 0 & 0 \\
\hline \multicolumn{7}{c}{ Fonte: autores $(2018)$}
\end{tabular}

O número de indivíduos coletados foi equivalente a aproximadamente 8,97 indivíduos por metro quadrado, o que torna o conhecimento acerca de tais comunidades de extrema relevância para a conservação da qualidade e biodiversidade dos solos urbanos (PATUCCI, 2017). Para o solo, a capacidade de espécies de macrofauna se movimentarem horizontal e verticalmente ajuda diretamente na distribuição de materiais orgânicos e minerais em profundidade por meio das galerias.

Assim, no quadrante 1, as capturas provenientes das pitfall traps $\mathrm{A}_{1}, \mathrm{~A}_{4}, \mathrm{~A}_{6} \mathrm{e} \mathrm{A}_{9}$ apresentaram maior ocorrência de Hymenoptera $(86,75 \%)$ e Araneae $(8,43 \%)$. Já no quadrante 2, com as pitfall traps $\mathrm{A}_{3}, \mathrm{~A}_{5}, \mathrm{~A}_{8}$ e $\mathrm{A}_{10}$, observou-se uma maior ocorrência de indivíduos da ordem Araneae $(9,13 \%)$, Hymenoptera $(89,04 \%)$ e Psocoptera $(0,91 \%)$.

No entanto, no quadrante 3, cujas pitfall traps eram $\mathrm{A}_{17}, \mathrm{~A}_{20}, \mathrm{~A}_{22}$ e $\mathrm{A}_{2} 5$, foram encontrados em maior número os indivíduos pertencentes às ordens Psocoptera $(4,48 \%)$ e Hymenoptera $(91,04 \%)$. Após a realização de estudo sobre invertebrados presentes no solo, em Santa Terezinha-PB, Costa et al. (2016) notaram que a abundância de indivíduos da ordem Hymenoptera estava estritamente ligada à harmonia na quantidade de indivíduos nas profundidades estudadas, além da relevância ecológica dos seres para mata ciliar.

Em relação ao quadrante 4, de pitfall traps $\mathrm{A}_{16}, \mathrm{~A}_{18}, \mathrm{~A}_{21}$ e $\mathrm{A}_{23}$, houve uma maior frequência de Hymenoptera $(86,21 \%)$, Araneae e Isoptera. Esse último é de suma importância para a fauna edáfica, já que influencia na estrutura do solo. Além de se organizarem em colônias e desempenharem uma função conforme sua especialização, fisiologia e morfologia. Sua maior ocorrência dá-se em zonas tropicais, entretanto também pode ser encontrado em ambientes temperados e desertos (BARRETA et al., 2011).

Além das pitfall traps dispostas em cada quadrante, também houve aquelas que se encontravam nas infralinhas, $\mathrm{A}_{2}, \mathrm{~A}_{7}, \mathrm{~A}_{14}, \mathrm{~A}_{15}, \mathrm{~A}_{19}, \mathrm{~A}_{24}, \mathrm{~A}_{11}$ e $\mathrm{A}_{12}$, e, por fim, o ponto fiduciário, A13, onde houve uma maior incidência de Hymenoptera (92,21\%), Araneae (5,19\%), Isoptera (1,30\%). No geral, os organismos pertencentes à macrofauna atuam na aglomeração do solo, na ciclagem de nutrientes e também na criação de poros. Além de agirem como controladores biológicos, através da predação de demais invertebrados (MACHADO et al., 2015).

\section{VEGETAÇÃO NA FLORESTA URBANA}

As observações in situ indicaram que a vegetação da área em estudo se encontrava escassa por apresentar somente a presença de gramíneas e pequenos arbustos cujo tamanho é insuficiente para gerar sombreamento. Dessa maneira, o solo apresentava alta exposição aos raios solares, no entanto, a árvore mais próxima do local de estudo, com uma distância de aproximadamente cinco metros e vinte centímetros, projetava sombra em uma parte da área e esta, apresentava gramíneas mais verdes se comparadas com as demais.

Quanto aos pequenos arbustos presentes, esses apresentavam algumas folhas com coloração amarelada, o que pode indicar a deficiência de nitrogênio no solo e resulta no amarelecimento das folhas mais velhas, pois o nitrogênio dessa planta é transferido para as folhas mais jovens (LOBO et 
al., 2012). Ademais, esses foram inseridos pelo homem e não de forma natural, pois estavam dispostos em linha reta. Além disso, foi constatado que havia pouca serapilheira sobre o local, em sua maior parte composta por capim seco possivelmente advindo de origem alóctone e algumas folhas que eram em pequena quantidade arrastadas pelo vento sendo essas originadas no sub-bosque.

Em relação ao vento, esse tinha sua direção mais frequente do Nordeste para o Sudoeste, como no lado Nordeste não havia a presença de sub-bosque, mas sim de asfalto, não havia a chuva de sementes nesse sentido o que dificultava a regeneração natural da área, uma vez que sementes que são advindas do próprio local favorecem a autorregeneração da floresta, já as transportadas por agentes que causam a dispersão, resultam no crescimento da diversidade genética e florística (SCCOTI et al., 2011).

Outro fator também observado foi a presença de uma unidade arquitetônica bem próxima ao local. A mesma consistia em um hotel revestido exteriormente por cerâmica na cor branca resultando em uma reflectância maior que incidia próxima a área de estudo aumentando ainda mais a incidência solar sobre a mesma. Além de que também havia um estacionamento coberto por asfalto e com uma distância de aproximadamente dois metros e trinta e cinco centímetros do local em questão, influenciando diretamente o mesmo, uma vez que materiais como pavimentos flexíveis, concreto, etc., possuem um saldo de radiação solar acima dos de áreas verdes, fato esse que resulta em temperaturas superiores (XAVIER et al., 2015), onde, por meio da ação do vento, essa massa de ar quente era deslocada para a área de estudo.

Ademais, havia a constante passagem de carro ao longo do dia o que resultava na liberação de gases poluentes como o dióxido de carbono, onde um dos fatores que se pôde observar como efeito desses gases poluentes sobre o local, foram os vestígios de que anteriormente havia a presença de vários líquens nas árvores onde poucos ainda se encontravam vivos, uma vez que esses são seres bioindicadores que repontam a poluição ambiental, o que modifica suas funções vitais ou acumula toxinas (FRANCO et al., 2009).

\section{RECOMENDAÇÕES}

- Não fazer a retirada da serapilheira presente no local, pois dificulta a reposição de matéria orgânica do solo.

- Plantio de arbustos com dossel abundante para que haja sombreamento na área e redução da exposição à radiação solar.

- A cor branca sobre a cerâmica do hotel possui albedo elevado e proporciona um conforto térmico para a parte interior do mesmo, no entanto aumenta a incidência solar sobre a área de estudo. Desta forma, pode-se optar pela utilização de parede vegetal no hotel, o que, além de proporcionar atenuação de temperatura, resulta na diminuição de reflectância de raios solares no local.

- Efetuar estudo e análise de macro e micronutrientes do solo para ter maior noção de sua resiliência e, desta forma, identificar elementos com escassez presente, para posterior reparação.

\section{CONCLUSÃO}

Os três parâmetros atmosféricos analisados apresentaram grande influência, pois, propiciam condições para os mecanismos de dispersão e desenvolvimento de sementes, o que favorece a regeneração natural da área. Porém, a escassez de espécies arbóreas de grande porte ocasiona a incidência direta de raios solares sobre o solo, o que o torna mais seco e dificulta o crescimento de pequenos arbustos.

A fauna de solo/pedofauna presentes, desenvolvem um papel de fundamental importância para o seguimento da reabilitação natural, visto que as funções exercidas, como movimentação, decomposição de matéria orgânica e ciclagem de nutrientes, contribuem para a promoção da qualidade do solo. 


\section{REFERÊNCIAS}

ALVES, L. W. R.; CARVALHO, E. J. M.; SILVA, L. G. T. Diagnóstico agrícola do município de Paragominas. Belém: Embrapa Amazônia Oriental, 2014.

AlVES, R. L.; PAlHetA, G. C.; ANDRADE, O. F. Paragominas se Torna Exemplo de Sustentabilidade Combatendo O Desmatamento Na Amazônia. Periódico Eletrônico Fórum Ambiental da Alta Paulista, v. 11, n. 7, nov. 2015.

AQUINO, A. M.; CORREIA, M. E. F. Invertebrados edáficos e o seu papel nos processos de solo. Seropédica: EMBRAPA SOLOS, 2005.

BARETTA, D. et al. Fauna edáfica e qualidade do solo. In: Tópicos em Ciência do Solo. Viçosa: Sociedade Brasileira de Ciência do Solo, v. 7, p. 119-170, 2011.

COSTA, R. M. C. et al. Abundância de invertebrados do solo em mata ciliar no semiárido da Paraíba. Gaia Scientia, v. 10, n. 4, 2016.

COSTA, J. M.; FLEURY, M. F. O programa "municípios verdes": estratégias de revalorização do espaço em municípios paraenses. Ambiente \& Sociedade. São Paulo, v. 18, n. 2, p. 61 - 76, 2015.

MICROSOFT EXCEL OFFICE. Gerenciador de planilhas eletrônicas. [S.I.]: Microsoft

GALEANO, D. C.; BIUDES, M. S.; DANELICHEN, V. H. M.; FABIAN, F. A.; SOUZA, M. C. Balanço de energia numa pastagem no Pantanal. Journal of Biotechnology and Biodiversity, Gurupi, v. 4, n. 2, p. 113-118, 2013.

GARTLAND, L. Ilhas de calor: como mitigar zonas de calor em áreas urbanas. Tradução Sílvia Helena Gonçalves. São Paulo: Oficina de Textos, 2010.

GERHARDT, T. E.; SILVEIRA, D. T. Métodos de Pesquisa. Porto Alegre: Editora da UFRGS. 2009.

IBGE. INSTITUTO BRASILEIRO DE GEOGRAFIA E ESTATÍSTICA. Cidades. 2017. Disponível em: <https://cidades.ibge.gov.br/brasil/pa/paragominas/panorama>. Acesso em 23 ago. 2018.

LABAKI, L. C. et al. Vegetação e conforto térmico em espaços urbanos abertos. Fórum Patrimônio: Ambiente Construído e Patrimônio Sustentável, v. 4, n. 1, 2011.

LAGO, A.; PÁDUA, J. A. O que é ecologia. São Paulo: Brasiliense, 2017.

LANDIM, Fátima L. P. et al. Uma reflexão sobre as abordagens em pesquisa com ênfase na integração qualitativo-quantitativa. Revista Brasileira em Promoção da Saúde, v. 19, n. 1, p. 53 $58,2012$.

LOBO, D. M. et al. Características de deficiência nutricional do amendoinzeiro submetido à omissão de N, P, K. Bioscience Journal, v. 28, n. 1, 2012.

LUNAS, M. C. F. S.; RIBAS, L. M. L. R. Parques urbanos municipais em Dourados - MS - Brasil: estado da arte. Redes, v. 18, n. 2, p. 231-245. 2013. 
MASCARO, J. J. Significado ambiental-energético da arborização urbana. Revista de Urbanismo e Arquitetura, v. 7, n. 1, 2008.

MUSCOLO, A. et al. Biological indicators to assess short-term soil quality changes in forest ecosystems. Ecological indicators, v. 45, p. 416-423, 2014.

PATUCCI, N. N. et al. Inventário de fauna edáfica como instrumento na avaliação de qualidade e biodiversidade de solos urbanos: estudo de caso do parque CienTec. Boletim Paulista de Geografia, n. 96, p. 66-90, 2017.

PORTO, M.L.; JESUS, E.S.; PEREIRA JÚNIOR, A. Análise das tendências nas relações entre fluxo de veículos, arborização e os níveis de intensidade de ruído. Ecologia e nutrição Florestal, v. 5, n.3, p. $87-97,2017$.

RUPPERT, E.E.; BARNES, R.D. Zoologia dos Invertebrados. 6 ed. São Paulo: Rocca, 1996.

SANTOS, D. D.; MORAES, S. L.; GALVANI, E. Variação da temperatura do ar média, mínima e máxima no perfil topoclimático da trilha caminhos do mar (SP). Revista Equador, v. 5, n. 5, p. 01$19,2016$.

RODRIGUES, A. G.; BORGES-MARTINS, M.; ZILIO, F. Bird diversity in an urban ecosystem: the role of local habitats in understanding the effects of urbanization. Iheringia, Sér. Zool., Porto Alegre, v. 108, 2018. Disponível em: http://www.scielo.br/pdf/isz/v108/1678-4766-isz-108e2018017.pdf. Acesso em: 30 jan. 2019

SALBITANO, F. et al. Guidelines on urban and peri-urban forestry. FAO, 2016.

SÁNCHEZ, L. E. Avaliação de Impacto Ambiental: conceitos e métodos. 2. ed. São Paulo: Oficina de Textos, 2013.

SANTANA, C. A. A.; FREITAS, W. K.; MAGALHÃES, L. M. S. Estrutura e similaridade em florestas urbanas na região metropolitana do Rio de Janeiro. Interciencia, v. 40, n. 7, 2015.

SCCOTI, M. S. V. et al. Mecanismos de regeneração natural em remanescente de Floresta Estacional Decidual. Ciência Florestal, v. 21, n. 3, p. 459-472, 2011.

SCORIZA, R. N.; CORREIA, M. E. F. Fauna do solo como indicadora em fragmentos florestais na encosta de Marrotes. Embrapa Agrobiologia-Artigo em periódico indexado (ALICE), 2016.

SCORIZA, R. N.; CORREIRA, M. E. F.; SILVA, E. M. R. Colêmbolos e fungos micorrízicos arbusculares como indicadores de degradação em fragmentos florestais de encosta. Revista de Ciências Agrárias/Amazonian Journal of Agricultural and Environmental Sciences, v. 59, n. 4, p. 386, 2016.

XAVIER, A. L. et al. Estudo da influência de diversos tipos de morfologia urbana no microclima do campus da Universidade Federal de Mato Grosso. Uniciências, v. 10, n. 1, 2015. 
Ana Júlia da Silva Moura Acadêmica de Engenharia Ambiental

Universidade do Estado do Pará Departamento de Engenharia Ambiental

moura.anajuliasilva@gmail.com

Kevin de Oliveira Moura Acadêmica de Engenharia Ambiental

Universidade do Estado do Pará

Departamento de Engenharia Ambiental kevinlol221@hotmail.com

Letícia Picanço da Silva

Acadêmica de Engenharia Ambiental

Universidade do Estado do Pará

Departamento de Engenharia Ambiental

leticiapicanco@hotmail.com

Rafael Dias Bicalho

Acadêmico de Engenharia Ambiental

Universidade do Estado do Pará

Departamento de Engenharia Ambiental

Antônio Pereira Júnior

Mestre em Ciências Ambientais

Universidade do Estado do Pará

Departamento de Engenharia Ambiental

antonio.junior@uepa.br 